\title{
An Overview to Neuromarketing and its Application
}

\section{Mahsa Akbari*}

Department of Business Management, Science and Research Branch, Islamic Azad University, Tehran, Iran.

\section{ABSTRACT}

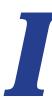

ntroduction: One of the major issues in consumer behavior is to understand consumer decision making process which always attracts scholars, marketers and managers. After disappointment from traditional methods, new emerging and combined methods have been developed, such as neuromaketing approaches. The combination of neuro and marketing implies the merging of two branches of science (neuroscience and marketing). Neuromarketing is a new field of marketing research that studies consumers' cognitive and affective responses to marketing stimuli. Researchers use technologies, such as functional magnetic resonance imaging electroencephalogram and eye-tracking methods, to measure changes in the brain activity to improve our understanding on how consumers make the decisions and what part of their brain is involved in this decision. Despite the perceived advantages of neuromarketing, some marketing scholars are reluctant to apply these neuroscience methods and there is still uncertainty about neuromarketing. Conclusion: The purpose of this review is to delineate a clear and comprehensive picture of neuromarketing as well as to address functional and empirical aspects of neuromarketing tools. A better understanding of neuromarketing may increase our knowledge in its fundamental implications with marketing and management.

\section{Key words:}

1. Marketing

2. Neurosciences

3. Neuroimagin

\section{* Corresponding Author: Mahsa Akbari}

E-mail:akbari.mahsa@gmail.com 


\section{مرورى بر بازاريابى عصبى و كاربردهاى آن}

$$
\text { مهرسا اكبرى" }
$$

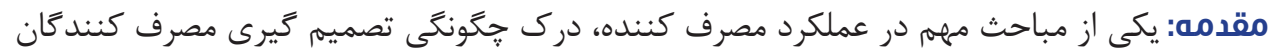

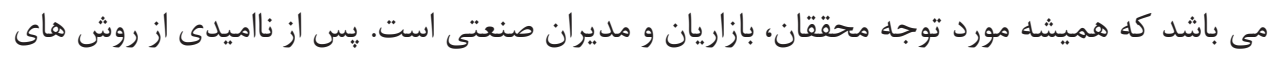

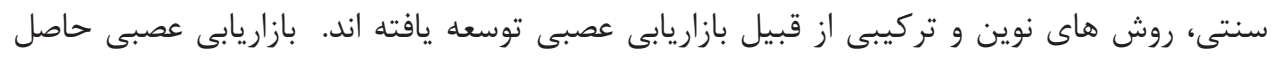

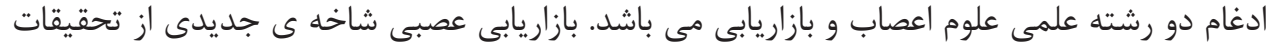

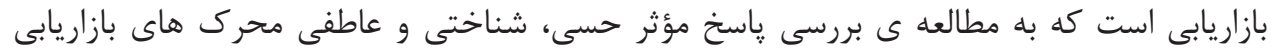

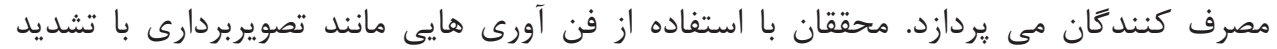

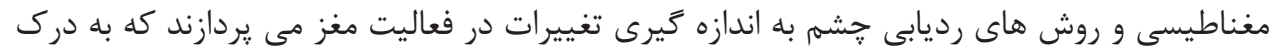

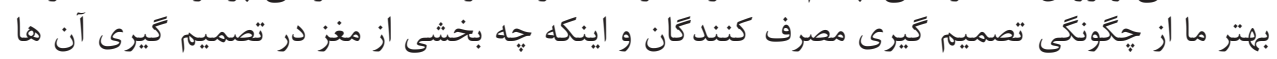

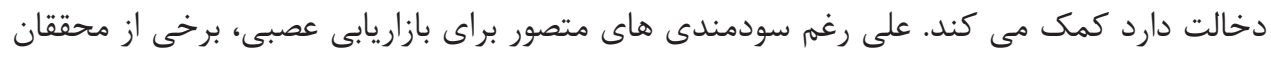

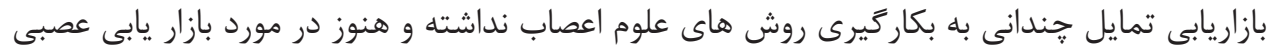

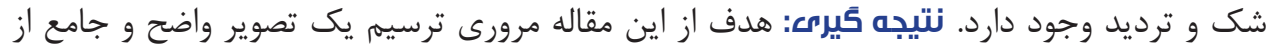

كليد وازه ها:

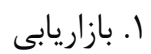
r. ( بلوم اعصاب

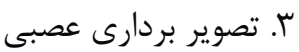

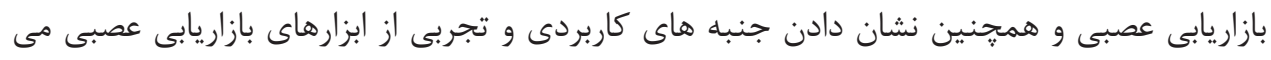

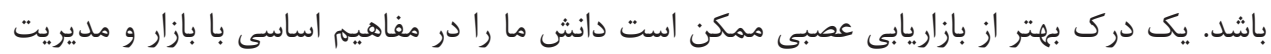
افزايش دهد.

$$
\text { " نويسنده مسئول: مهرا اكبرى }
$$

آدرس الكترونيكى: akbari.mahsa@gmail.com 
بازاريابى عصبى يديده اى نوظهور است كه يافته هاى آن دريجه

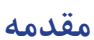

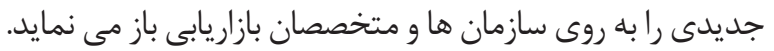
هدف اين يزوهش آن است كه با توصيف مفاهيم و ابزارهاى باري

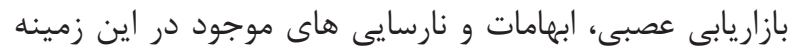

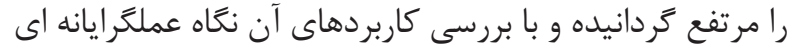

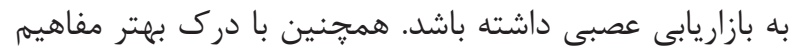

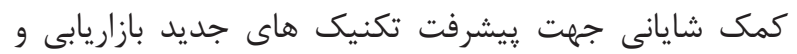
يياده سازى آن ارائه دهد. تاريخجه بازاريابى عصبى

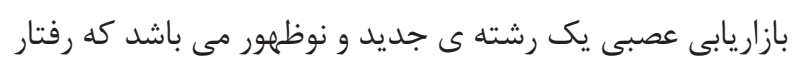

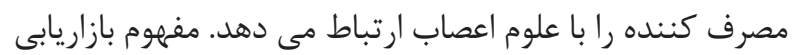

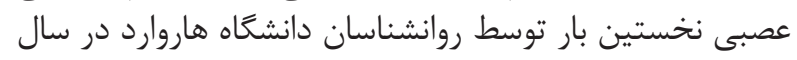

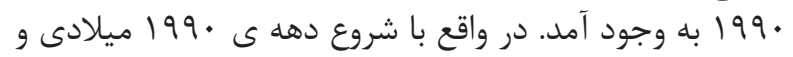

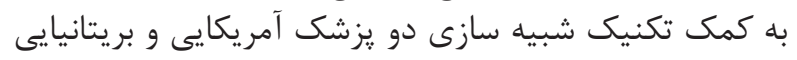

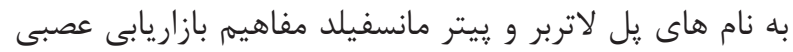

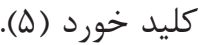

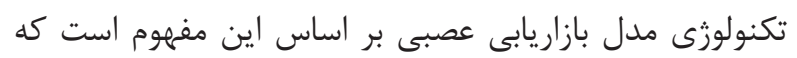

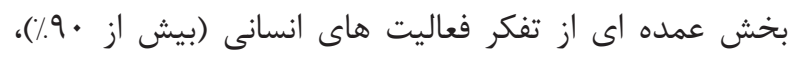

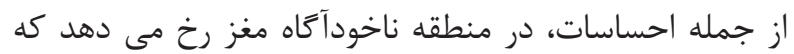

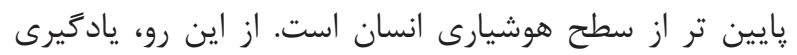

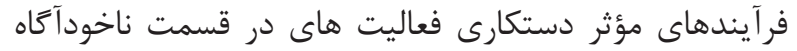
مغز همواره مورد توجه بازاريان بوده است.

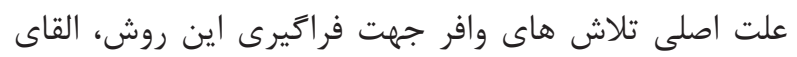

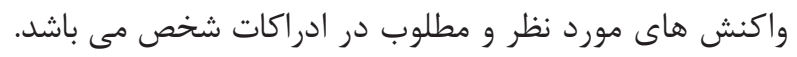

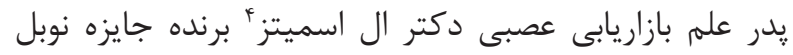

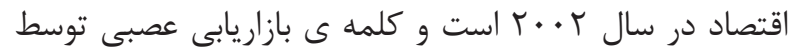

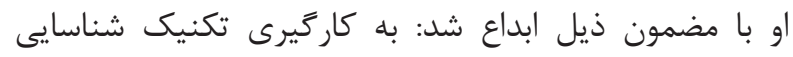

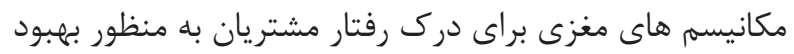
استراتزى هاى بازاريابى است (ه).

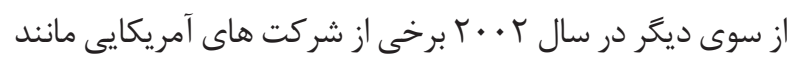

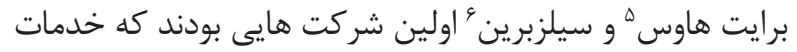

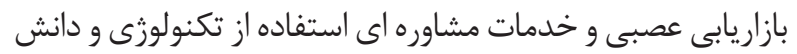

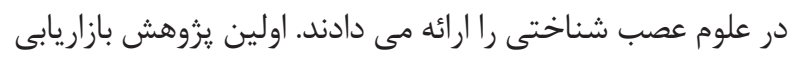

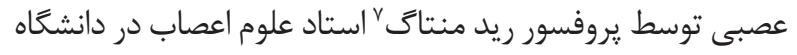

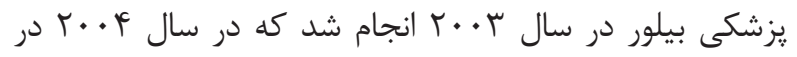

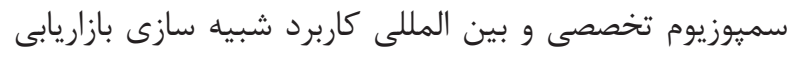

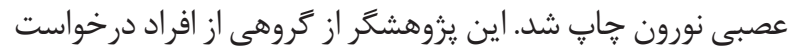

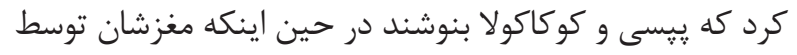

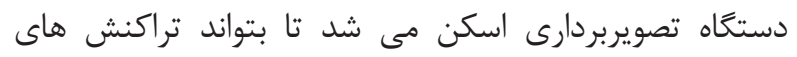

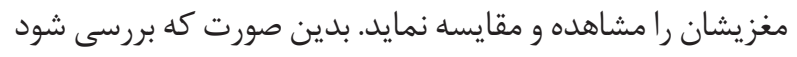

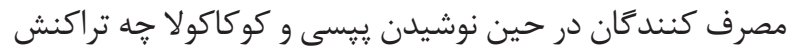

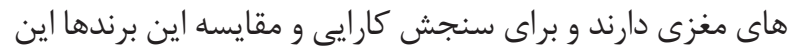

تراكنش ها را با هم مقايسه نمايد (9).

${ }^{1}$ Neuroeconomic

${ }^{2}$ Neuromarketing methodology

${ }^{3}$ Neuroscience

${ }^{4}$ Ale Smidts

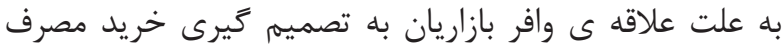

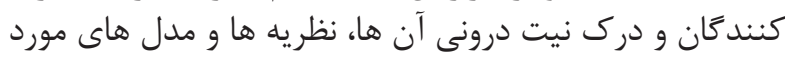

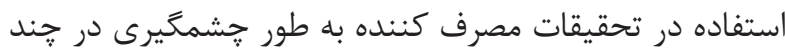
سال كذشته تغيير يافته است (1).

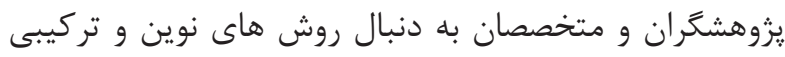

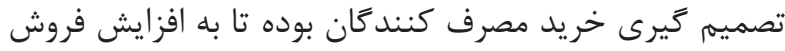

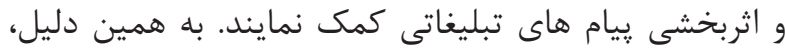

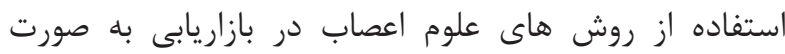

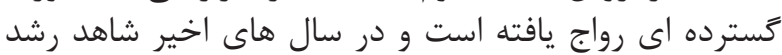

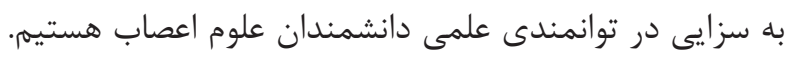

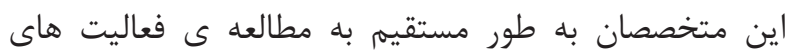
قشرى مغز در زمان، مكان و فر كانس هاى مختلف مى ير يردازند.

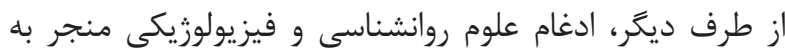

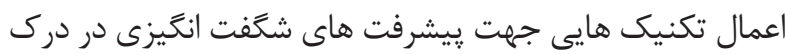

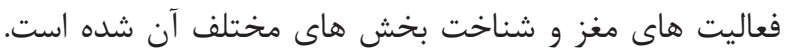

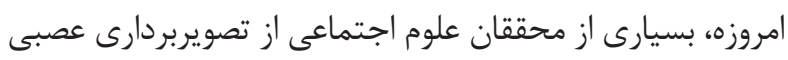

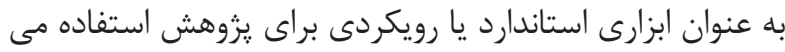

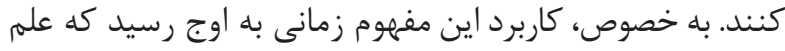

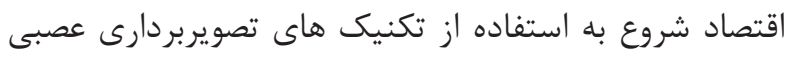

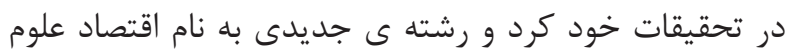
اعصاب' به وجود آمد (r) (r).

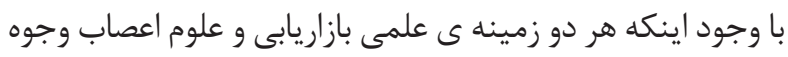

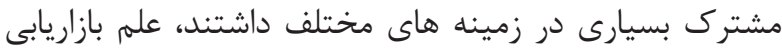
تا مدت ها متوجه مزاياى استفاده از تكنيك هاى دئل تصويربردارى

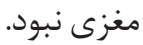

دلايل محتمل زيادى براى عدم استفاده از روش شئ شناسى هاى

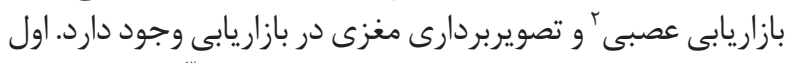

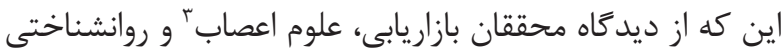

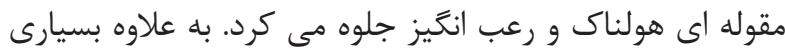

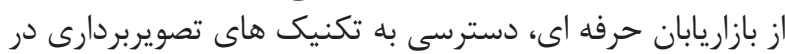
واحدهاى تخصصى خود را ناممكن مئ دارئ دانستند.

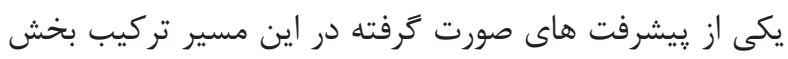

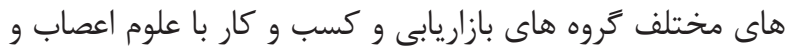

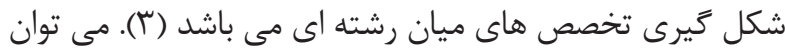

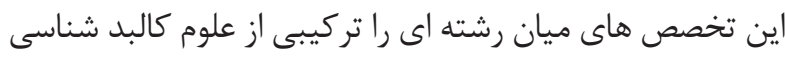

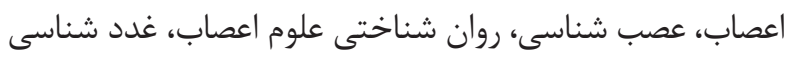

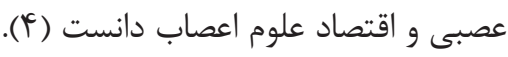

همجنين به كاركيرى روش هاى بازاريابى عصبى فراتر از روش

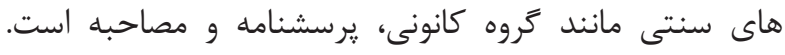

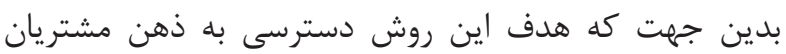

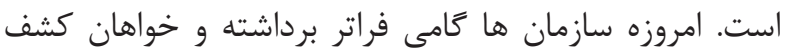

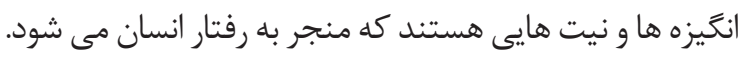

\footnotetext{
${ }^{5}$ Bright House

${ }^{6}$ Sales Brain

${ }^{7}$ Read Montague
} 
بوده و برنده است. بر اساس گززارشات منتشر شده قشر ميانى

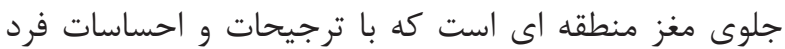

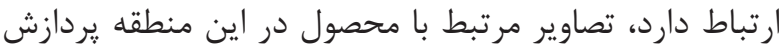

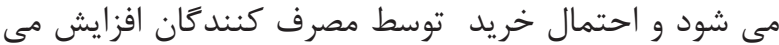

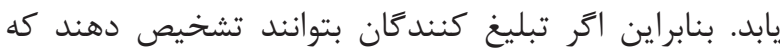

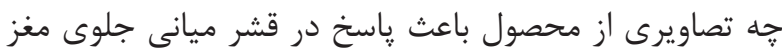
مى شود، آن ها قادر خواهند بود كه فروش راعث را تقويت نمايند.

در تقسيم بندى هاى مطالعات بازاريابى اختلاف نظر وجود

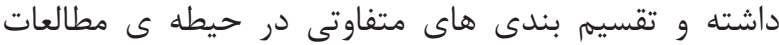

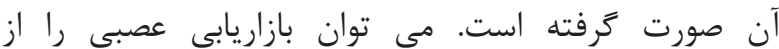

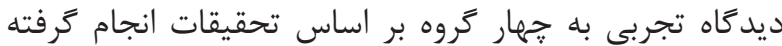

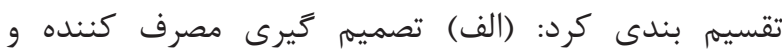

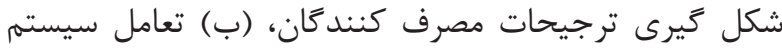

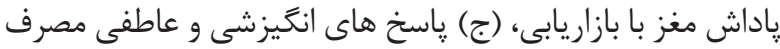

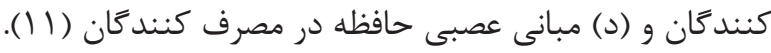

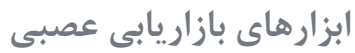

تكنيك ها و ابزارهاى متفاوتى در بازاريابى عصبى توسط بإي

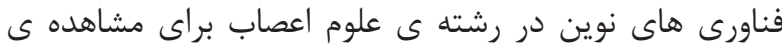

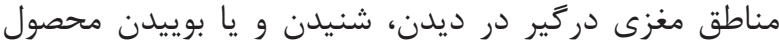

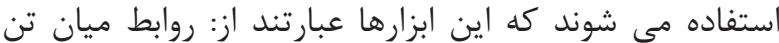

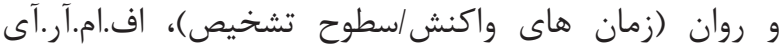

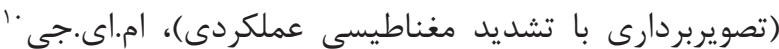

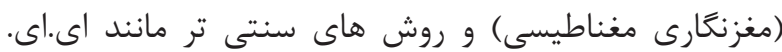

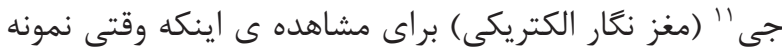

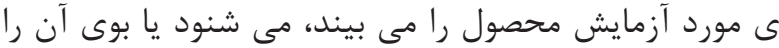

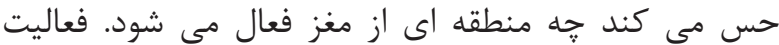

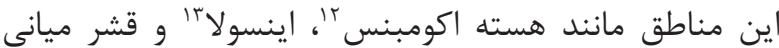

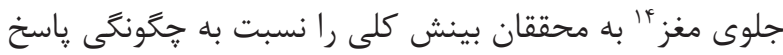

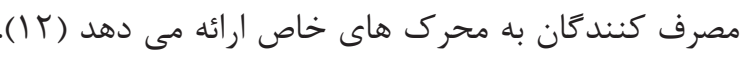

بر اساس تحقيقاتى كه در زمينه ى بازاريابى عصبى روى تكنيك

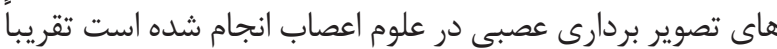

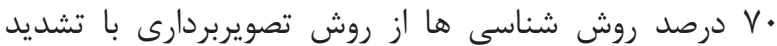

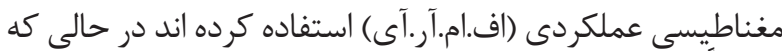

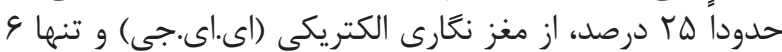

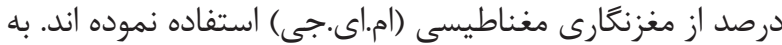

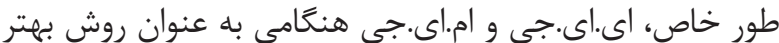

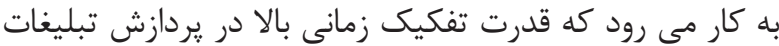

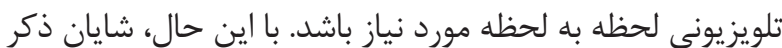

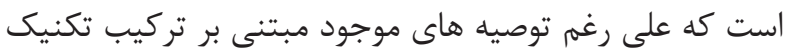

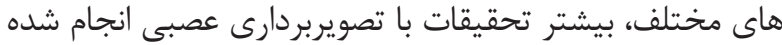

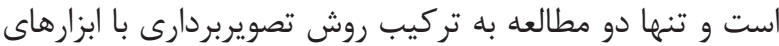

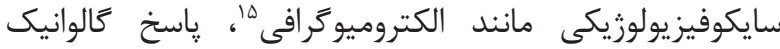
يوست" و ضربان قلب يرداخته است (بان (1).

\footnotetext{
8 Antonio Damasio

${ }^{9}$ fMRI (functional Magnetic Resonance Imaging)

${ }^{10}$ MEG (Magnetoencephalography)

${ }^{11}$ EEG (Electroencephalography)

12 Accumbens
}

تعريف بازاريابى عصبى

تاكنون تعاريف بسيارى براى بازاريابى عصبى توسط محققان و ورئ

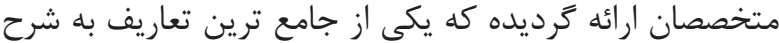

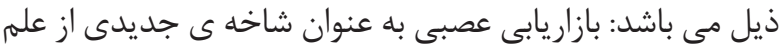

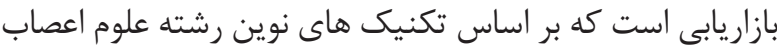

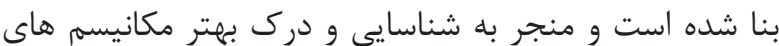

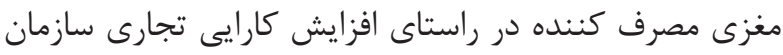

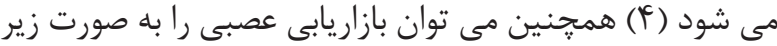

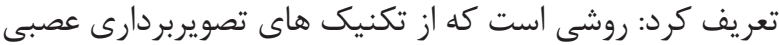

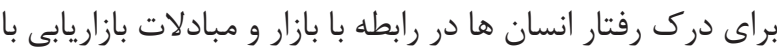

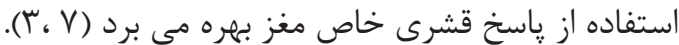

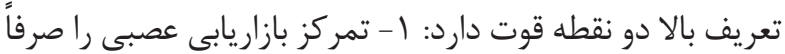

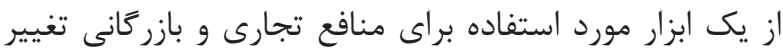

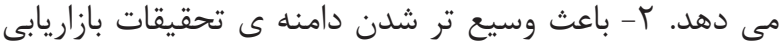

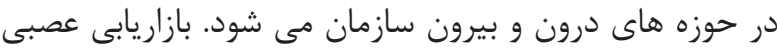

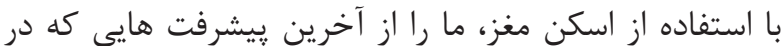

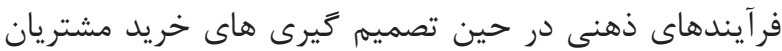

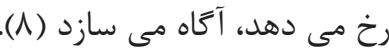
اخر بخواهيم به ريشه يابى بازاريابى عصبى بيردازيم مى توان إنى إنى

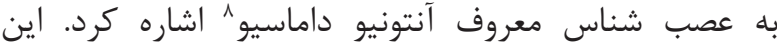

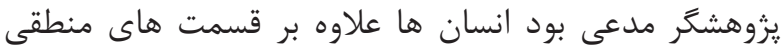

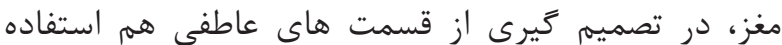

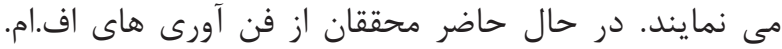

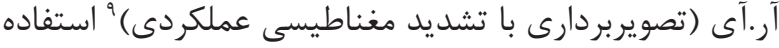

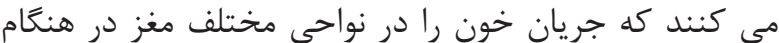

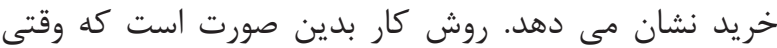

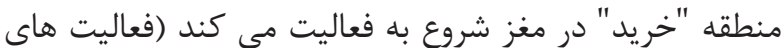

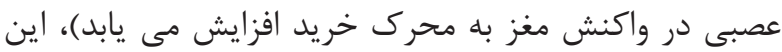

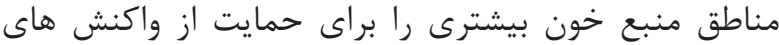

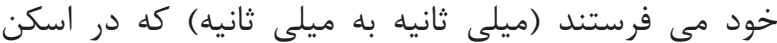

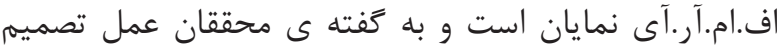

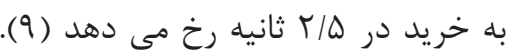
علاوه بر اين، بازاريابى عصبى به شدت وابسته به توانايى تجسم

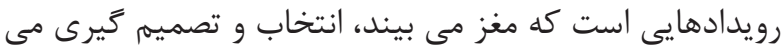

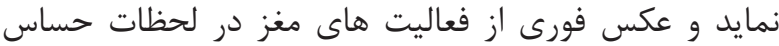
خريدهاى عمده و جزئى فراهم معى نمايد (• (1). در يروهش هاى انجام شده در بازايابى عصبى، قشر ميانى جلوى ترى

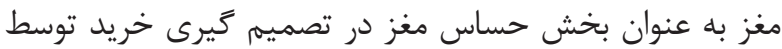

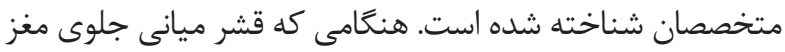

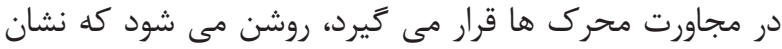

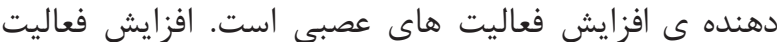

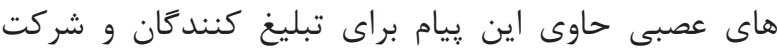
هاى تبليغاتى است كه تصوير يخش شده بـ به به احتمال زياد مؤثر

13 Insula

${ }^{14}$ Mesial prefrontal cortex

${ }^{15}$ EMG (Electromyography)

${ }^{16}$ GSR (Galvanic Skin Response) 
كه از مطالعات اف.ام.آر.آى و اي.اى.جى بدست آورده اند لزوماً

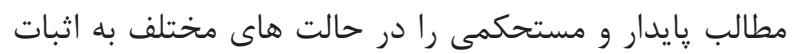

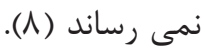
در يزوهش حاضر روى سه تكنيك اصلى تصوير بردارى يعنى

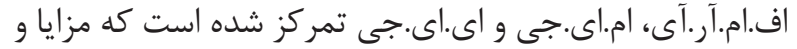

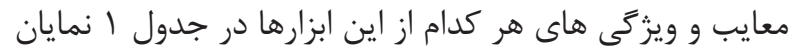

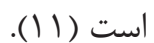

عملكرد مغز در ياسخ به خريدهاى بالقوه به صورت زير است (9):

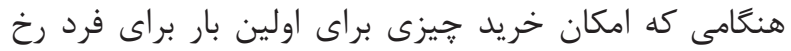

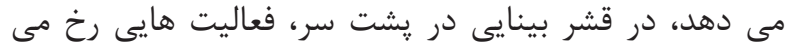

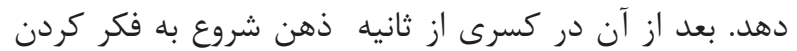

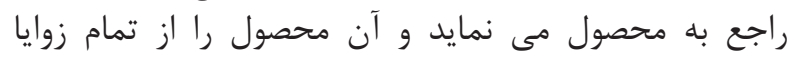

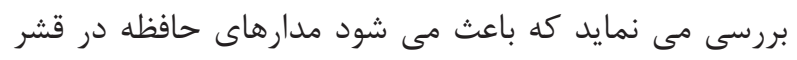

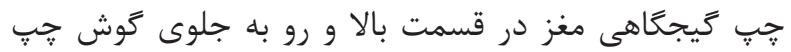

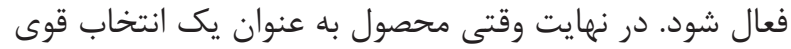
يرترجيح ثبت مى شود كه هدف تمامى تبليغ كنندكان همين
شركت ها با استفاده از دستخاه هاى تصويربردارى بهتر مى توانند

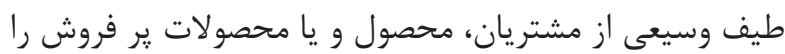

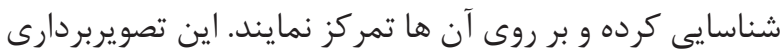

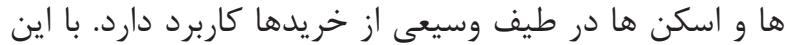

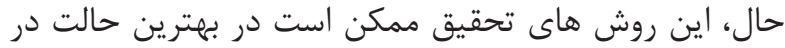
مرحله ى طفوليت در نظر كرفته شوند (^).

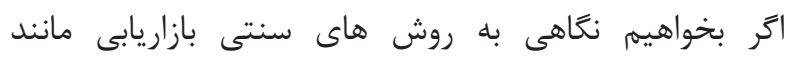

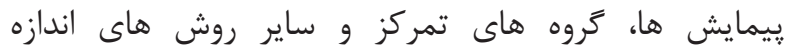

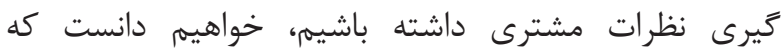

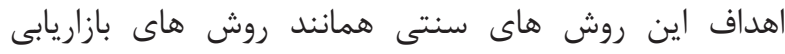

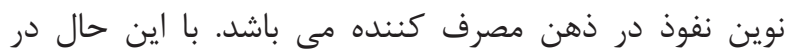

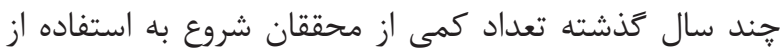

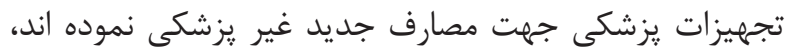

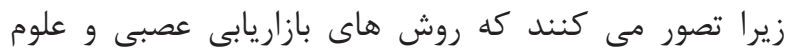

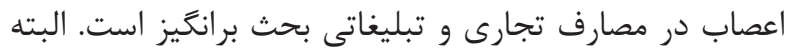

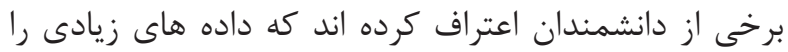

جدول ا- مقايسه تى تكنيك هاى بازاريابى عصبى (1)

\begin{tabular}{|c|c|c|c|c|}
\hline معايب & مزايا & تكنولوزى & نحوه ى اندازه گيرى & نام تكنيك \\
\hline 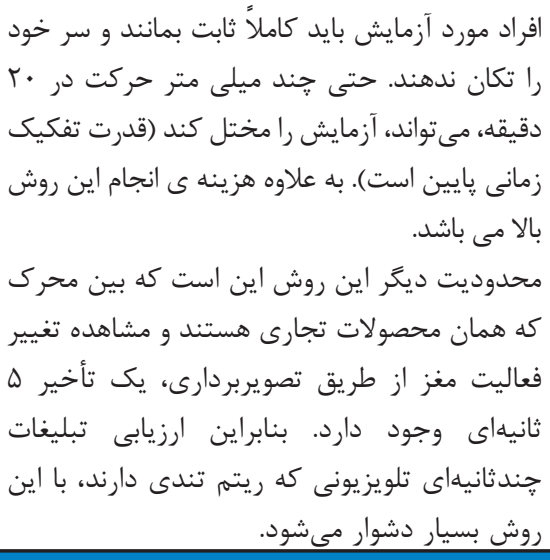 & 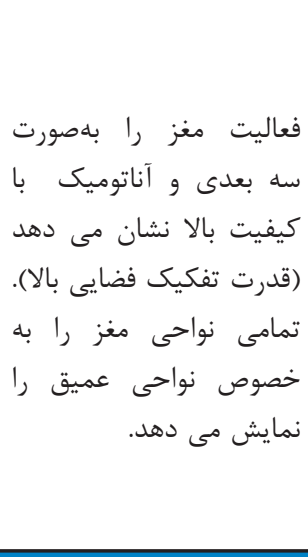 & 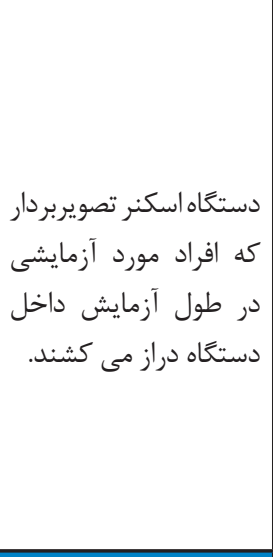 & مشاهده م تغييراتى كه در & تصويربردارى \\
\hline قسته به تعداد الكترودها نمايش قايين (حدود ا سانتى دهد). & 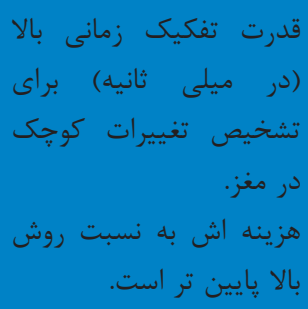 & 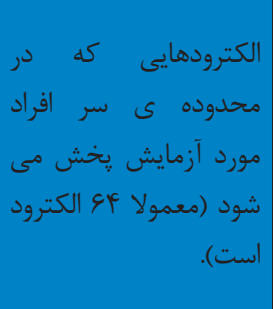 & 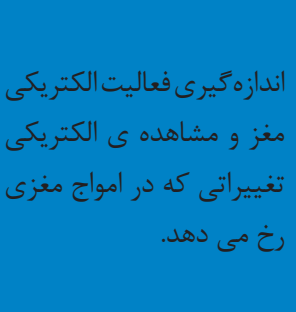 & الكتريكى (اى. مغزنار. \\
\hline قدرت تفكيك فضايى هايين و هزينه اين روش به & قدرت تفكيك زمانى بالا در. & 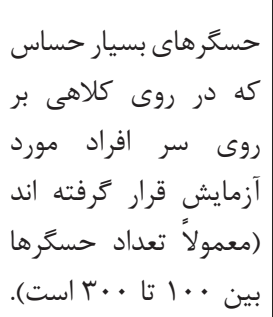 & 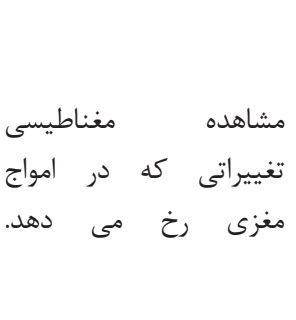 & مغناطيسى (ام. مغزار \\
\hline
\end{tabular}




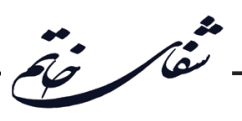

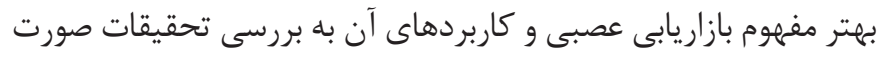

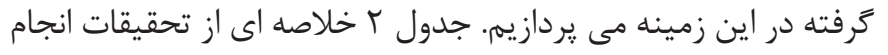

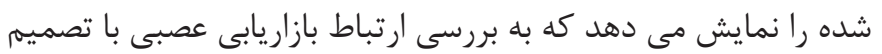

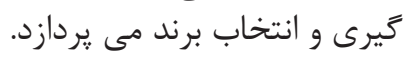

است، اين عمل به قشر جدارى سمت راست مغز كه در بالاو و

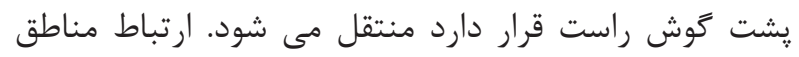

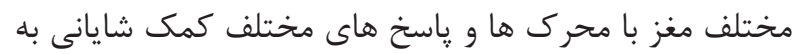
تحقيقات بازاريابى عصبى میى كند.

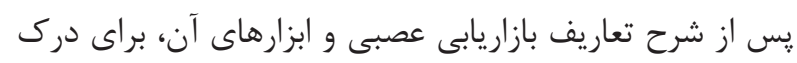

جدول r- خلاصه اى از تحقيقات انجام شده در زمينه بى بازاريابى عصبى (^)

\begin{tabular}{|c|c|c|}
\hline سوالات تحقيق & موضوع تحقيق & نو يسنده \\
\hline | آيا امكان دارد ارتباط عصبى بين ارزيابى جذابيت & 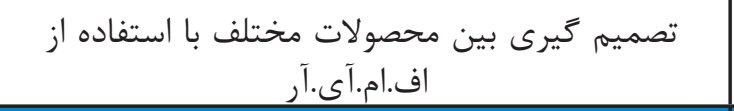 & $\begin{array}{l}\text { Erk et al. } \\
(2002)\end{array}$ \\
\hline 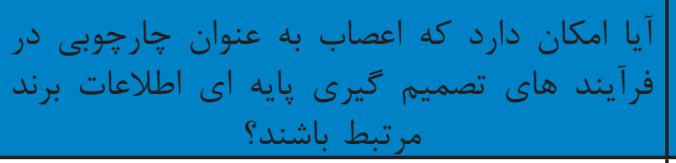 & 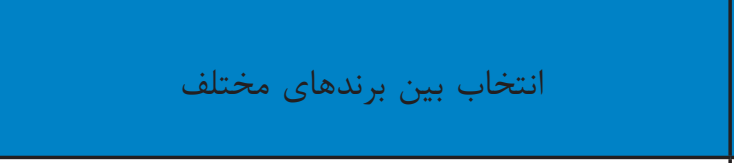 & $\begin{array}{l}\text { Deppe et al. } \\
\quad(2005)\end{array}$ \\
\hline 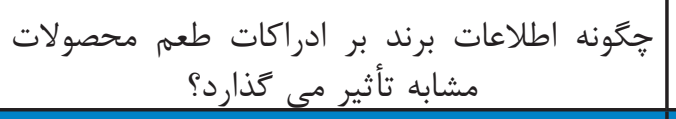 & |انتخاب بين برندها و محصولات مختلف و ادراى طعم & $\begin{array}{l}\text { McClure et al. } \\
\text { (2004) }\end{array}$ \\
\hline | جَّونه افراد مشهور بَر يادسيارى برند تأثير مى & تأثير تبليغاتى افراد مشهور و ستاره با استفاده از آ.آر & $\begin{array}{c}\text { Klu_charev et al. } \\
(2005)\end{array}$ \\
\hline 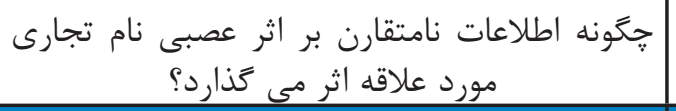 & ارتباط بين برندهاى خدماتى مختلف با استفاده از آل آل & $\begin{array}{c}\text { Plassmann et al. } \\
\text { (2006) }\end{array}$ \\
\hline فادارى برند وجود دارد؟ & 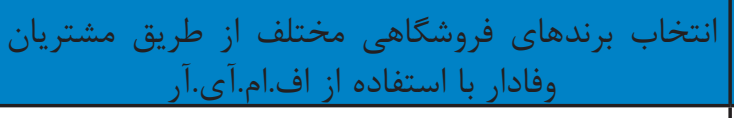 & $\begin{array}{l}\text { Plassmann et al. } \\
\text { (2006) }\end{array}$ \\
\hline |عصاب جه تأثيرى بر برندهاى مرتبط با فرهنَ & انتخاب بين برندهاى مختلف ماشين با استفاده از إ.إ.ایى & $\begin{array}{l}\text { Schaefer et al. } \\
\text { (2006) }\end{array}$ \\
\hline ل آيا بين شخصيت انسان ها و شخصيت نام تجارى & انتخاب بين برندهاى مختلف & $\begin{array}{l}\text { Yoon et al. } \\
\text { (2006) }\end{array}$ \\
\hline 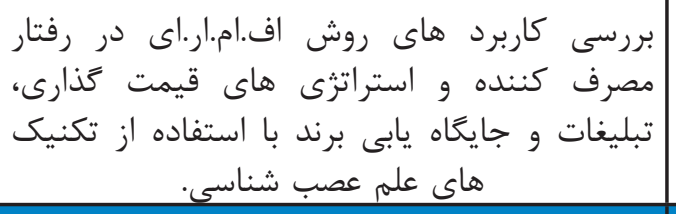 & كاربرى هاى اف.ام.آر.آى در تحقيقات بازاريابى & $\begin{array}{l}\text { Kenning et al. } \\
\quad(2007)\end{array}$ \\
\hline |تأثيرات علم عصب شناسى را بر بازاريابى و رفتار & مغز و برندها: توسعه يزوهش هاب اطوابلاعاتى در حوزه ى & $\begin{array}{l}\text { Perrachione et al. } \\
\qquad(2008)\end{array}$ \\
\hline 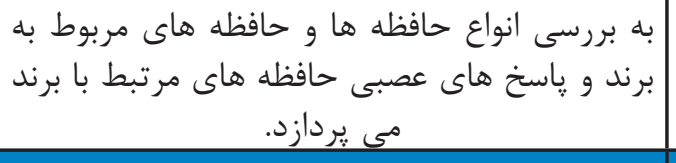 & رويكرد عصب شناختى به يادسيارى نام تجارى & $\begin{array}{c}\text { Ratnayake et al. } \\
\text { (2010) }\end{array}$ \\
\hline 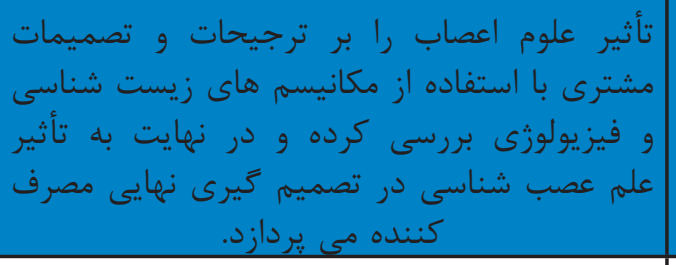 & تصميم كيرى در علوم اعصاب و رفتار مصرف كننده & $\begin{array}{l}\text { Yoon et al. } \\
\text { (2012) }\end{array}$ \\
\hline 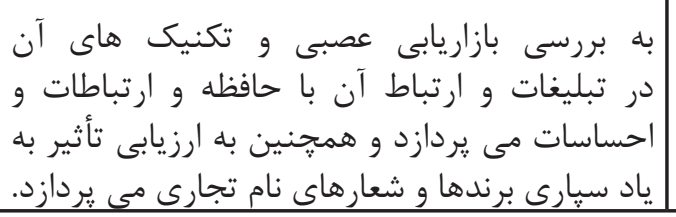 & ذهن مصرف كننده: ادراى نام تجارى و مفاهيم آن براى & $\begin{array}{l}\text { Amy Parsons } \\
\text { (2013) }\end{array}$ \\
\hline
\end{tabular}


كاربردهاى بازاريابى عصبى

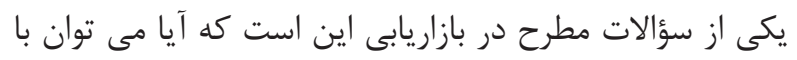

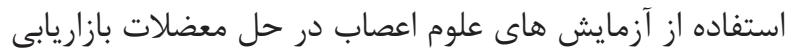

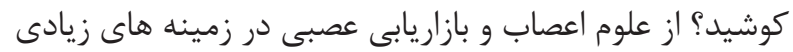

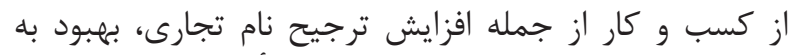

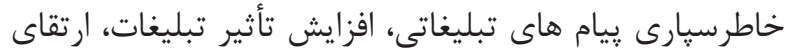

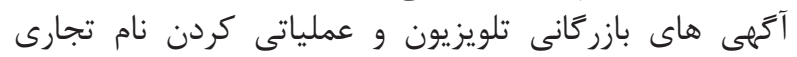

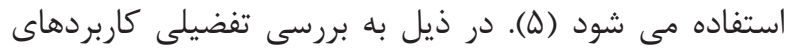

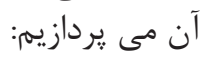

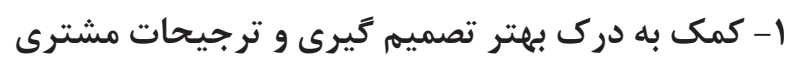
امروزه در سراسر جهان بيش از •و آزمايشكاه علوم اعصاب

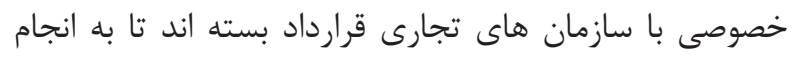

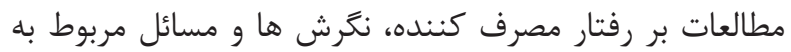

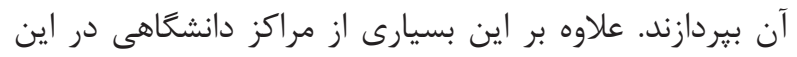

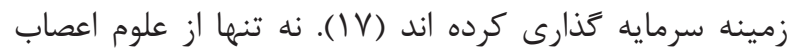

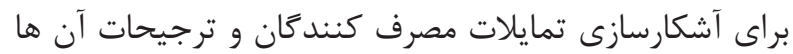

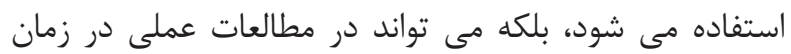

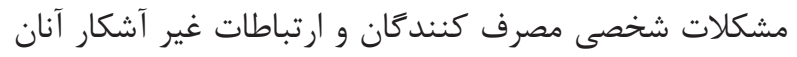

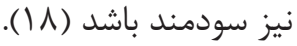

\section{r- ارتقاى تبليغات تجارى}

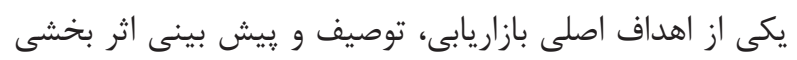

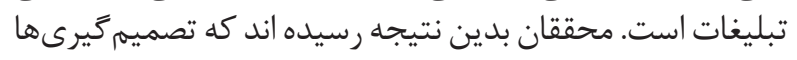

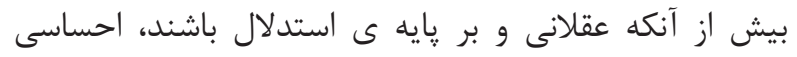

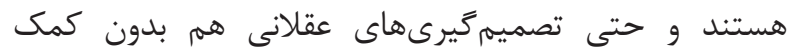

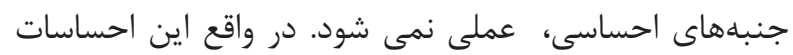

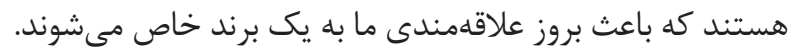

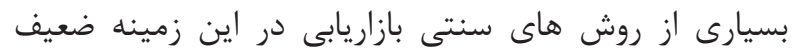

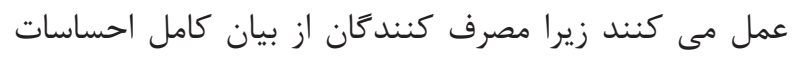

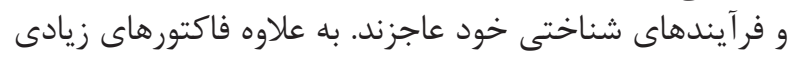

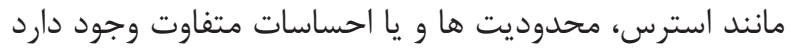

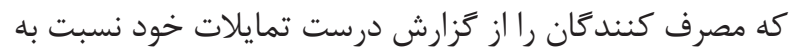

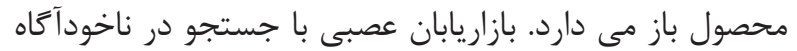

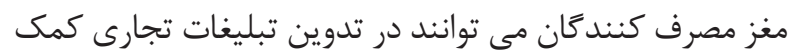

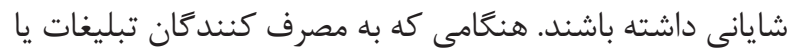

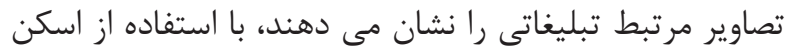

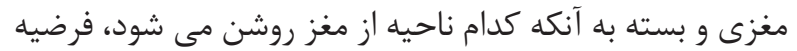

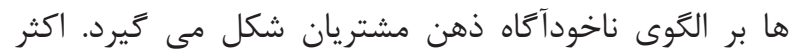

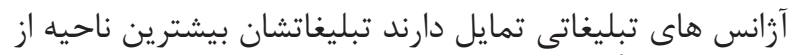

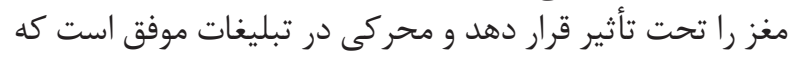

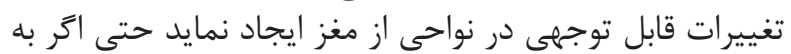

خريد هم منجر نشود (19).

\section{r- بهبود محصولات و جذابيت هاى آن}

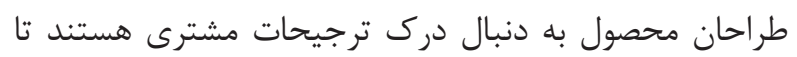

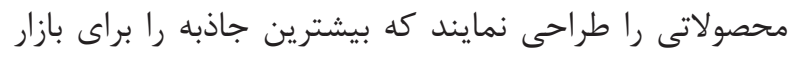

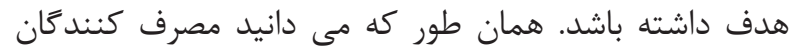

مفهوم دكمه خى خريد

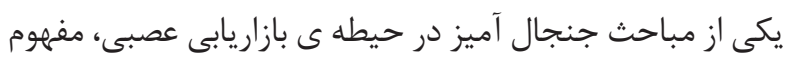

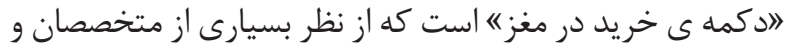

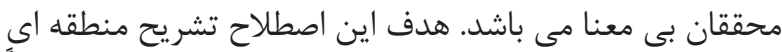

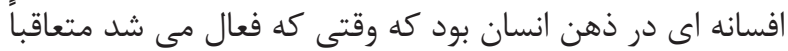

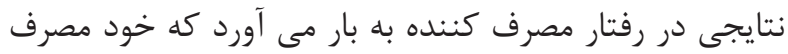

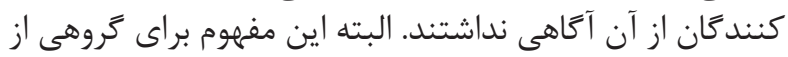

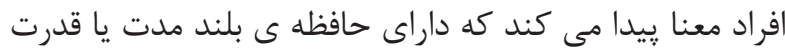

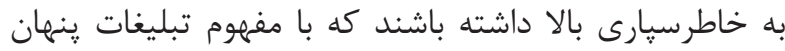

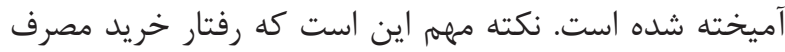

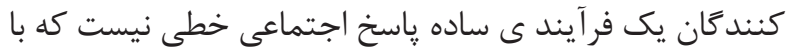

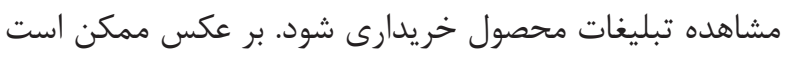

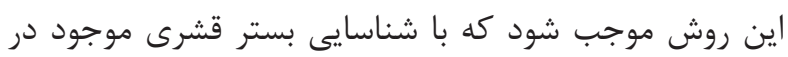

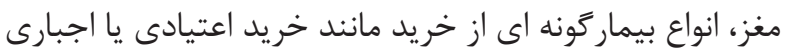

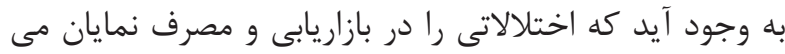

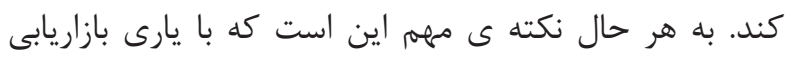

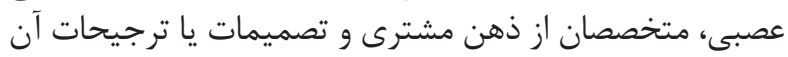

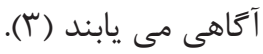

سه مغز تصميم كَيرنده

مغز مسئول تمامى تصميمات مصرف كننده مى بـ باشد. تحقيقات

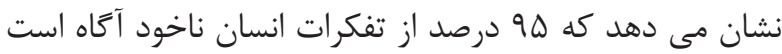

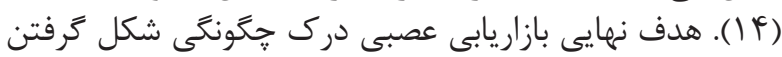

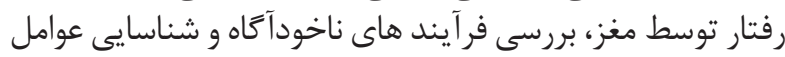

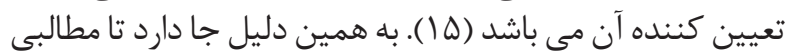

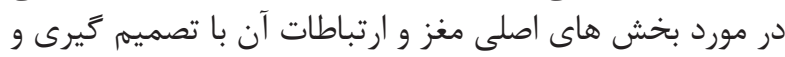

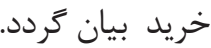

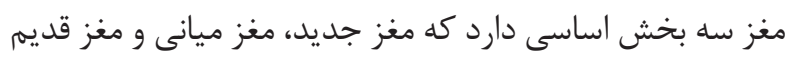

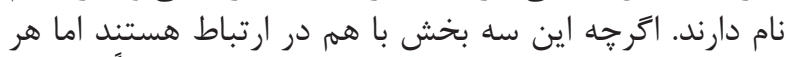

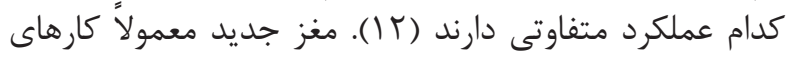

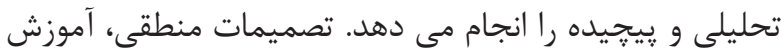

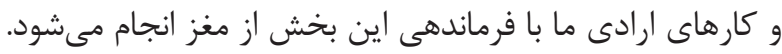

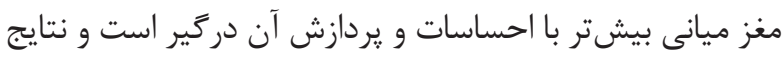

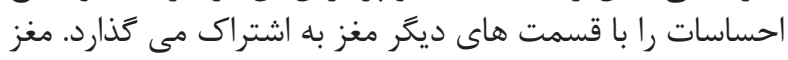

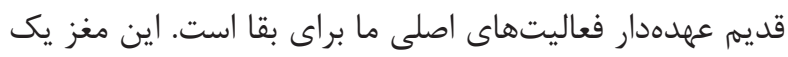

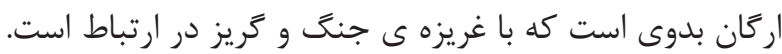

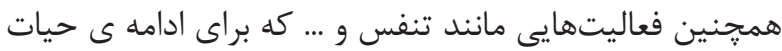

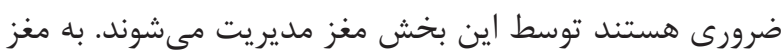

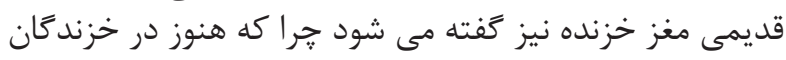

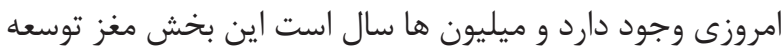
يافته و پيام هاى يِيجيده را متوجه نمى شود (1) (1). نكته ى درخور توجه اين است كه اغلب تصميمات غيرارادى و

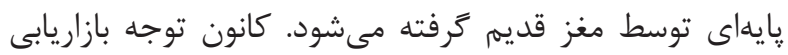

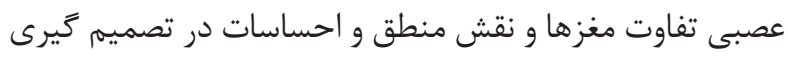

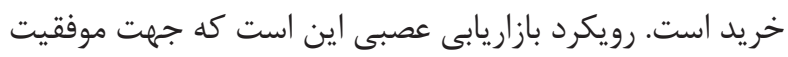
در فروش بايد بر روى مغز قديم تمركز كردا رئ 
معضلات اخلاقى باز اريابى عصبى در دو دسته عمده قرار دارد

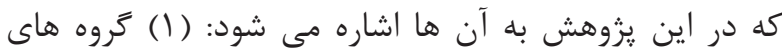

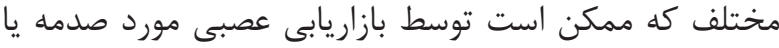

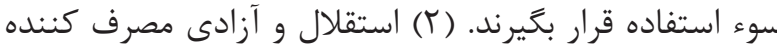

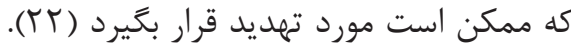

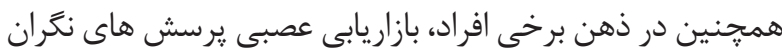

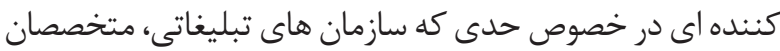

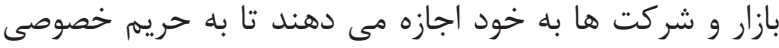

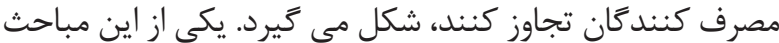

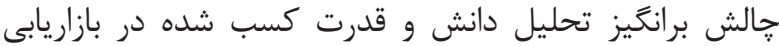

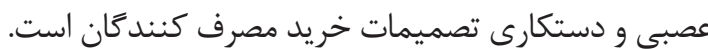

بررسى سؤالاتى از اين نوع كه آيا بازاريابى عصبى تنها يكى روش

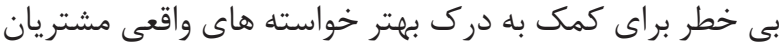

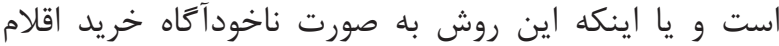

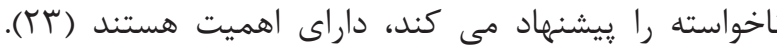

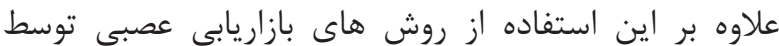

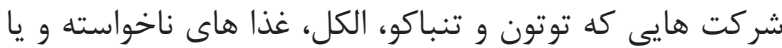

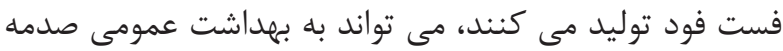

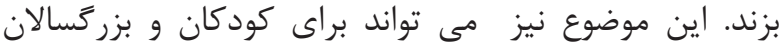

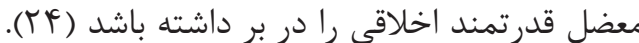

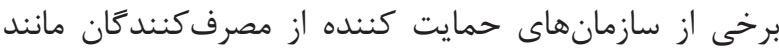

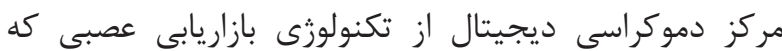

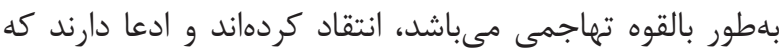

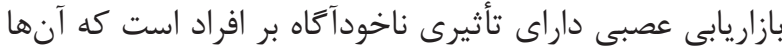

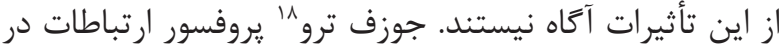

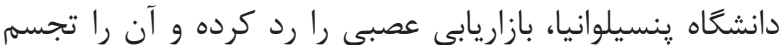

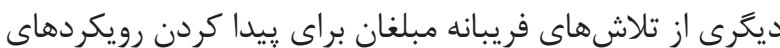

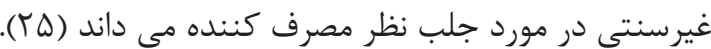
هر ساله كنفرانس اخلاقيات عصبى 19 در ارويا بركزار

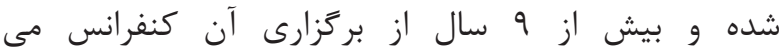

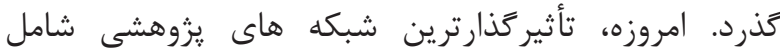

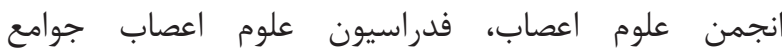

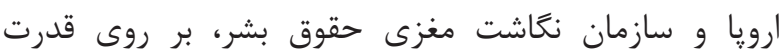

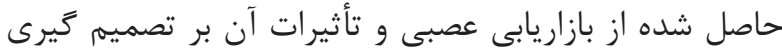

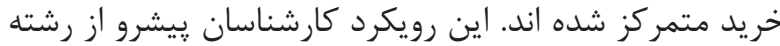

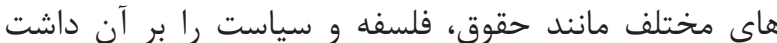

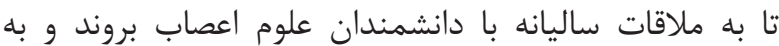

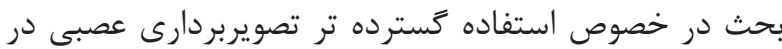

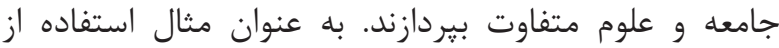

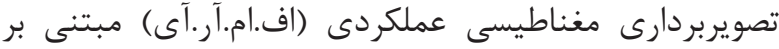

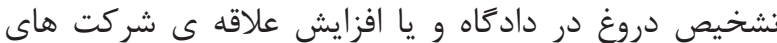

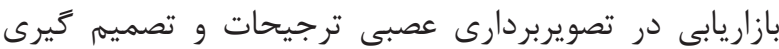

مصرف كننده (Y) - (ب).

${ }^{17}$ Mental Involvement

${ }^{18}$ Joseph Turow

19 Neuroethics
تحت تأثير جامعه، فرهنَ و انتظارات يايه ایى خود هستند. به به

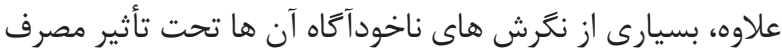

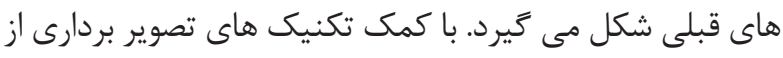

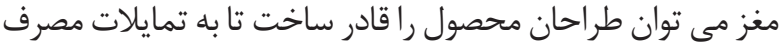

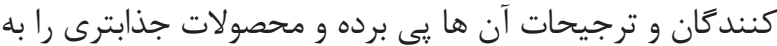

بازار ارائه نمايند (9) (19).

\section{F - ايجاد و Fسترش نام تجارى (برند) و عملياتى كردن آن}

با استفاده از ابزارهاى بازاريابى عصبى، مى تونى توان از نيت مشتريان

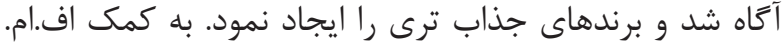

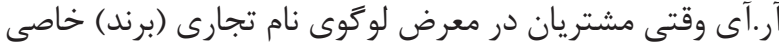

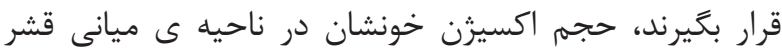

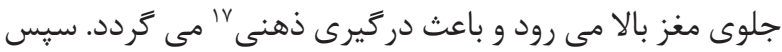

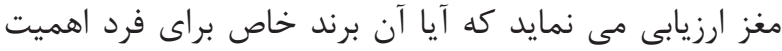

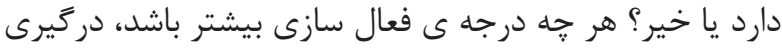

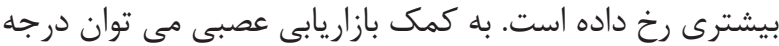

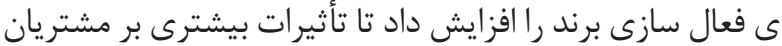

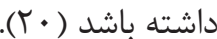

\section{ه- افزايش تأثيرات تبليغات}

با توجه به اين واقعيت كه ما همه روزه با انبوهى از يُ ييامهاى

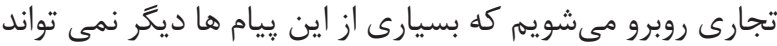

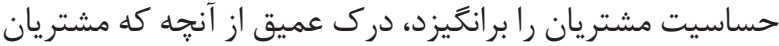

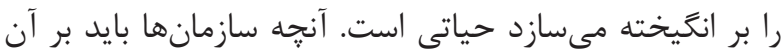

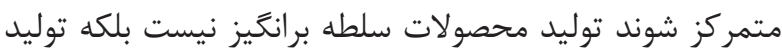

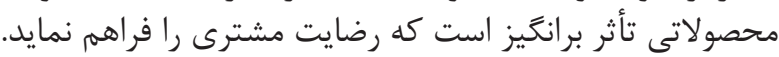

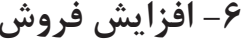

تكنولوزى بازار يابى عصبى در ايجاد برندو افزايش فروش سازمان ها

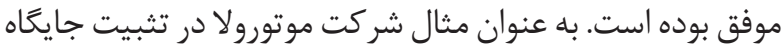

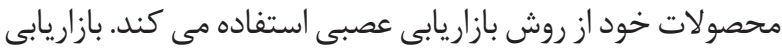

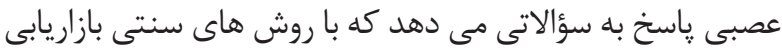

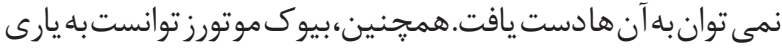
بازاريابى عصبى فروش نمان نمايند

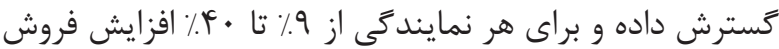

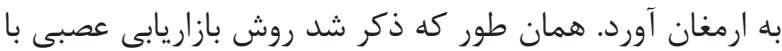

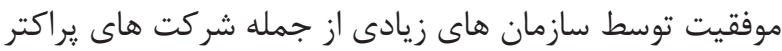

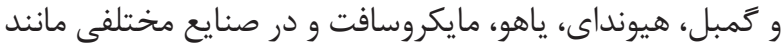

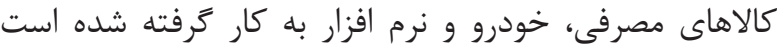

انتقادات اخلاقى در بازاريابى عصبى يكى از معضلات بازاريابى عصبى بحث مسائل اخلاقى است.

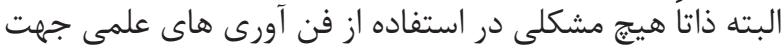

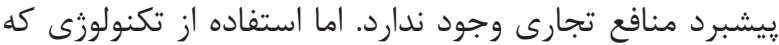

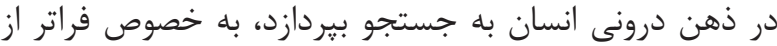

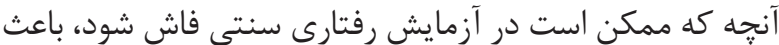

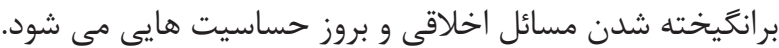


راستاى بهببود برندها و مارك هاى تجارى اقدامات قابل توجهى

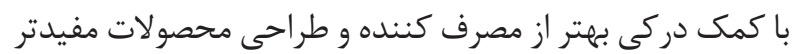

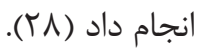

عليرغم سودمندى هاى متصور، بازاريابى عصبى هنوز در مراحل

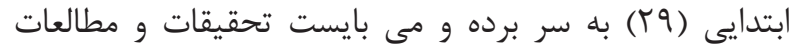

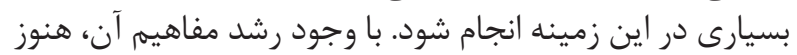

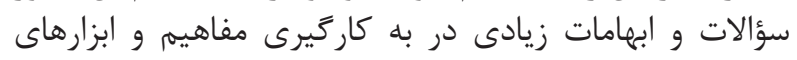

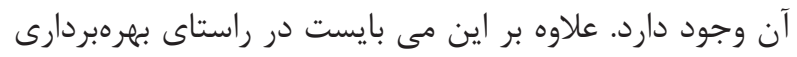

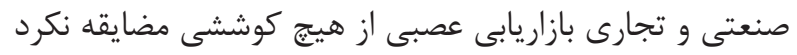

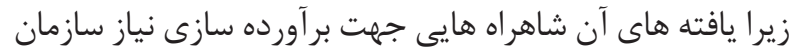
ها گشوده است.

اين مقاله ضمن ارائه ى تاريخٌه، تعاريف و ابزارها به شرح اين

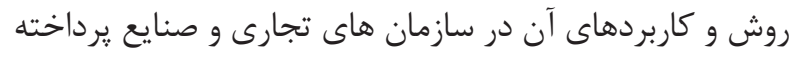

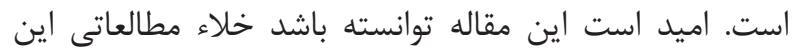

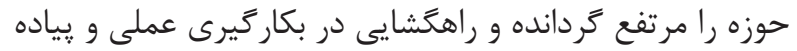

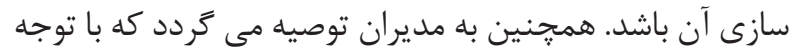

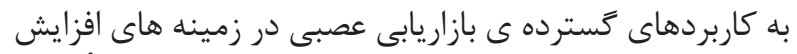

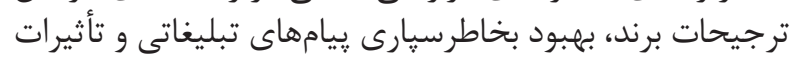

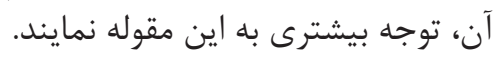

1. Bagozzi RP, Gopinath M, Nyer PU. The role of emotions in marketing. J Acad Market Sci. 1999; 27(2): 184-206.

2. Kenning P, Plassmann H. Neuroeconomics: An overview from an economic perspective. Br Res Bull. 2005; 67(5): 343-54.

3. Lee N, Broderick A, Chamberlain L. What is 'neuromarketing? A discussion and agenda for future research. Int J Psychol. 2007; 63: 199-204.

4. Gazzaniga MS, Ivry RB, Mangun GR. Cognitive Neuroscience: The Biology of the Mind. 3rd ed. New York: Hardcover. 2008; p. 30-45.

5. Veronica B. Brief History of Neuromarketing. J Bert Rus. 2009; 119-21.

6. Morin C. Neuromarketing: The New Science of Consumer Behavior. Symposium: Consumer Culture in Global Perspective. 2011; 48: 131-5.

7. Weinstein S, Drozdenko R, Weinstein C. Brain wave analysis in advertising research. Psychol Market. 1984; 1: 83-96.

8. Eser Z, Isin B, Tolon M. Perceptions of marketing
نتيجه تيرى

امروزه استفاده از تكنيك هاى سنتى بازاريابى مانند يرسش نامه،

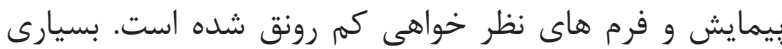

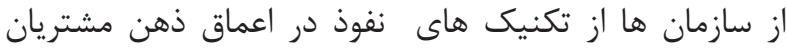

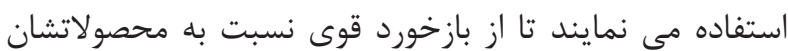

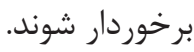

با توجه به حجم بالاى تبليغات در رسانه هاى عمومى، علوم

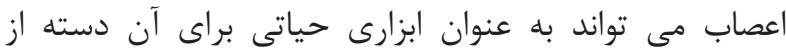

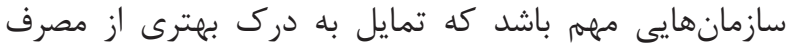

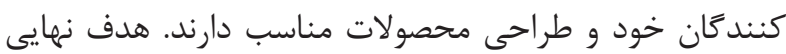

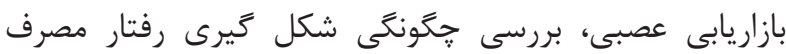

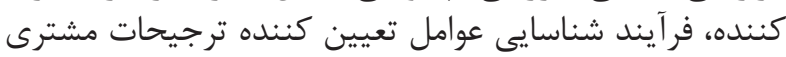

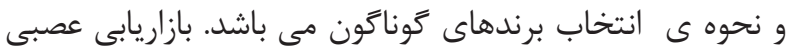

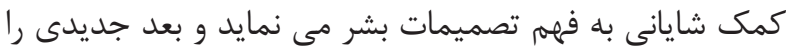

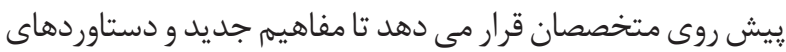
نوين را نهادينه سازند (YV)

بازاريابى عصبى رويكردهايى در تحقيقات كمى ارائه مى دهد كه

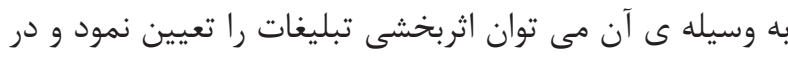

academics, neurologists and marketing professionals about neuromarketing. J Market Mange. 2011; 27: 854-68.

9. Witchalls C. Pushing the buy button. Newsweek, 2004. http://www.commercialalert.org/issues/culture/ neuromarketing/pushing-the-buy-button.

10. Burne J. Inside the mind of the shopper: Neuromarketing Financial Times. 2003; 13.

11. Solnais C, Andreu-Perez J, Sanchez-Fernandez J, Andréu-Abela J. The contribution of neuroscience to consumer research: A conceptual framework and empirical review. J Econ Psychol. 2013; 36: 68-81.

12. Moore K. Maybe it is like brain surgery. Marketing. 2005; 12: 110-15.

13. Kable JW. The cognitive neuroscience toolkit for the neuroeconomist: A functional overview. J Neurosci Psychol Econ. 2011; 4(2): 63-84.

14. Ciprian-Marcel P, Lacramioara R, Ioana MA, Maria ZM. Neuromarketing-getting inside the customer's mind. Annals of Faculty of Economics. 2009; 4(1): 804-7. 


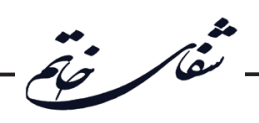

15. Wilson RM, Gaines J, Hill RP. Neuromarketing and Consumer Free Will. J Con Aff. 2008; 42(3): 389-410.

16. Peel A. Mapping the mind for the modern market researcher. Qual Market Res Int J. 2007; 2(10): 153-67.

17. Zurawicki L. Book Review: Neuromarketing: Exploring the Brain of the Consumer. Int J Res Mark. 2011; 53: 287-8.

18. Yoon C, Gonzalez R, Bechara A, Berns G, Dagher A, Dubé L. Decision neuroscience and consumer decision making. Market Lett. 2012; 23: 473-85.

19. Fugate LD. Neuromarketing: a layman's look at neuroscience and its potential application to marketing practice. J Consum Mark. 2007; 24(7): 385-94.

20. Madan RC. Neuromarketing: The Next Step in Market Research? Eureka. 2010; 1: 1-2.

21. Babu S, Vidyasagar TP. Neuromarketing: Is campbell in soup? J Mark Manage. 2012; 2.

22. Murphy E, Iles J, Reiner P. Neuroethics of neuromarketing. J Con Behav. 2008; 7: 293-302.

23. Ziegenfuss J. Neuromarketing: Evolution of advertising or unethical use of medical technology? Brown J. 2005; 12.

24. Acuff D. Taking the guesswork out of responsible marketing. Young Consumers: Insight and Ideas for Responsible Marketers. 2005; 6 (4): 68-71.

25. Singer N. Making Ads that whisper to the brain. The New York Times, 2010.

26. Connell G. Tracking the impact of neuroethics. Cortex. 2011; 4: 1259-60.

27. Touhami ZO, Benlafkih L, Jiddane M, Cherrah Y, Malki HL, Benomar A. Neuromarketing: Where marketing and neuroscience meet. Afr J Bus Manage. 2011; 5(5): 1528-32.

28. Glimcher PW, Camerer CF, Fehr E, Poldrack RA. Neuroeconomics: Decision Making and the Brain. New York: Academic Press. 2008

29. Karimi A. Benchmarking in traditional marketing; Neuro-marketing, something between influence and manipulation in customer behavior. Tad J. 2011. 